\title{
The efficacy of bedside chest ultrasound: from accuracy to outcomes
}

\author{
Mark Hew ${ }^{1,2}$ and Tunn Ren Tay ${ }^{1,3}$
}

\begin{abstract}
Affiliations: ${ }^{1}$ Allergy, Immunology and Respiratory Medicine, The Alfred Hospital, Melbourne, Australia. ${ }^{2}$ School of Public Health and Preventive Medicine, Monash University, Melbourne, Australia. ${ }^{3}$ Dept of Respiratory and Critical Care Medicine, Changi General Hospital, Singapore.
\end{abstract}

Correspondence: Mark Hew, Allergy, Immunology and Respiratory Medicine, The Alfred Hospital, 55 Commercial Road, Prahran, Melbourne, Victoria 3181, Australia. E-mail: m.hewdalfred.org.au

ABSTRACT For many respiratory physicians, point-of-care chest ultrasound is now an integral part of clinical practice. The diagnostic accuracy of ultrasound to detect abnormalities of the pleura, the lung parenchyma and the thoracic musculoskeletal system is well described. However, the efficacy of a test extends beyond just diagnostic accuracy. The true value of a test depends on the degree to which diagnostic accuracy efficacy influences decision-making efficacy, and the subsequent extent to which this impacts health outcome efficacy. We therefore reviewed the demonstrable levels of test efficacy for bedside ultrasound of the pleura, lung parenchyma and thoracic musculoskeletal system.

For bedside ultrasound of the pleura, there is evidence supporting diagnostic accuracy efficacy, decisionmaking efficacy and health outcome efficacy, predominantly in guiding pleural interventions. For the lung parenchyma, chest ultrasound has an impact on diagnostic accuracy and decision-making for patients presenting with acute respiratory failure or breathlessness, but there are no data as yet on actual health outcomes. For ultrasound of the thoracic musculoskeletal system, there is robust evidence only for diagnostic accuracy efficacy.

We therefore outline avenues to further validate bedside chest ultrasound beyond diagnostic accuracy, with an emphasis on confirming enhanced health outcomes.

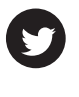

@ERSpublications

The next challenge in bedside chest ultrasound is to refocus from diagnostic accuracy toward patient outcomes http://ow.ly/NyNR3027WLU

\section{Introduction}

Point-of-care chest ultrasound is now an integral part of practice for many respiratory and critical care clinicians [1-3]. Its widespread adoption has been facilitated by the advent of portable high-performance scanners, and the transfer of skills from other ultrasound applications in respiratory medicine including endobronchial ultrasound [4-6]. However, the greatest single driver behind the expansion in bedside chest ultrasound is probably the identification of characteristic sonographic features for common thoracic conditions. The diagnostic accuracy of such ultrasound findings is high, especially for pleural and parenchymal abnormalities [1].

Yet diagnostic accuracy should not be the only consideration when evaluating a test such as chest ultrasound. Other aspects of test efficacy are also important, in particular the impact on patient outcomes [7]. Indeed, Fryback and Thornbury [8] proposed six levels of test efficacy relevant to medical imaging: technical efficacy, diagnostic accuracy efficacy, diagnostic thinking efficacy, therapeutic efficacy, patient outcome efficacy and societal efficacy $[8,9]$. We shall touch on each briefly, as our subsequent narrative is structured around these

Received: May 082016 | Accepted after revision: July 052016

Conflict of interest: None declared.

Provenance: Submitted article, peer reviewed.

Copyright OERS 2016. ERR articles are open access and distributed under the terms of the Creative Commons Attribution Non-Commercial Licence 4.0. 
levels of efficacy in relation to bedside chest ultrasound. To simplify discussion, we group these six levels of efficacy under three broad domains: test attributes, clinical decision-making and health outcomes (figure 1).

\section{Levels of chest ultrasound efficacy}

Test attributes comprise technical efficacy and diagnostic accuracy efficacy, which relate to the physical testing system. Technical efficacy for chest ultrasound encompasses machine characteristics, operator proficiency and the semiology of imaging findings. Diagnostic accuracy efficacy refers to test characteristics (e.g. sensitivity and specificity) for detecting various pathological conditions.

Clinical decision-making involves diagnostic thinking efficacy and therapeutic efficacy. These levels of efficacy relate to the cognitive impact of the test result on clinician behaviour [10]. Diagnostic thinking efficacy describes the usefulness of a test to influence a clinician's thinking. Therapeutic efficacy is the degree to which test results affect patient management, such as a decision regarding further testing or treatment.

Health outcomes consist of patient outcome efficacy and societal efficacy. These levels of efficacy reflect the test's impact on real-world outcomes. Patient outcome efficacy is probably the best measure of test value, since the main aim of medical care is to improve patient well-being. A recent example is the reduction in lung cancer mortality through chest computed tomography (CT) screening [11]. Societal efficacy is usually described in terms of cost-benefit and is often estimated by economic analyses. Randomised controlled trials (RCTs) can also be employed to address this question.

In general, the higher levels of test efficacy build upon the lower levels. Some degree of diagnostic accuracy is usually required to change clinician decision-making, which in turn is needed to improve final patient outcomes [10]. Of course, diagnostic accuracy does not always change decision-making, nor do changes in medical decision-making automatically confer outcome efficacy [12].

\section{Scope of this review}

The levels of test efficacy described above form a useful framework when evaluating the usefulness of a diagnostic test. The intention of this review is to summarise and appraise the evidence for bedside chest ultrasound at each level of test efficacy. We conclude by outlining future avenues to further validate bedside chest ultrasound beyond diagnostic accuracy, with an emphasis on demonstrating improved health outcomes.

Readers will find that substantial evidence is available for the lower levels of chest ultrasound efficacy (figure 1). Yet even here, some uncertainties remain around the diagnostic accuracy for common conditions. At higher levels of test efficacy, less evidence for benefit exists. This issue requires attention, since chest ultrasound only confers real-world value if health outcomes are improved.

In this review, we define chest ultrasound as sonography of the pleura, the lung parenchyma and the thoracic musculoskeletal system. Echocardiography is not included.

\section{Test attributes: technical and diagnostic accuracy efficacy}

This section will be discussed according to three anatomical areas: pleural syndromes, comprising pneumothorax and pleural effusion; parenchymal syndromes, comprising lung consolidation and the interstitial syndrome; and musculoskeletal syndromes, comprising chest wall and diaphragm abnormalities.

\section{Six levels of efficacy}

Test attributes

1) Technical efficacy

2) Diagnostic accuracy efficacy

Decision-making

3) Diagnostic thinking efficacy

4) Therapeutic efficacy

Health outcomes

5) Patient outcome efficacy

6) Societal efficacy
Available evidence

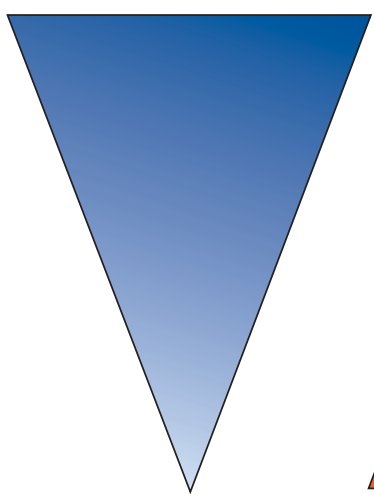

\section{Clinical impact}

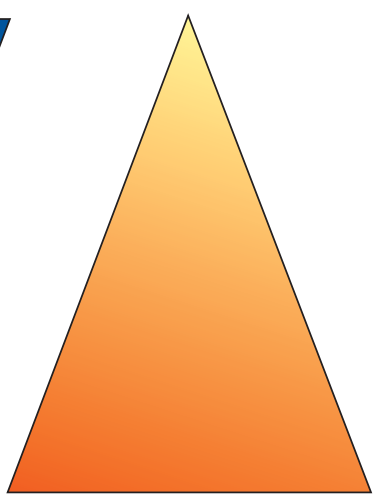

FIGURE 1 Levels of diagnostic test efficacy [8] depicting the available evidence for bedside chest ultrasound at each level and the relative clinical impact. 


\section{Pneumothorax}

Ultrasound is used to diagnose pneumothorax. Three sonographic features have been described: the absence of "lung sliding", the absence of "B-lines" and the presence of "lung point" (table 1).

"Lung sliding" is a to and fro movement along the pleural line in time with respiration $[1,13]$. This gives a granular lung artefact on M-mode termed the "sea-shore sign" (figure 2a). An associated finding is "lung pulse", where the pleural line moves in time with transmitted cardiac pulsations [1]. The presence of lung sliding or lung pulse always excludes pneumothorax in the area scanned. The absence of lung sliding is suggestive of, but not specific for, pneumothorax [13]. The absence of lung sliding causes a linear artefact on M-mode known as the "bar-code sign" (figure 2b). Importantly, hyperinflation in chronic obstructive pulmonary disease (COPD) [14] and pleural adhesions [15] can also cause loss of lung sliding (table 1).

"B-lines" (figure 2c) are vertical artefacts projecting from the pleural line to the bottom of the screen that move with respiration $[1,16]$. The presence of B-lines excludes pneumothorax, but their absence does not confirm it [17].

"Lung point" has been defined as "the absence of any sliding or moving B-lines at a physical location where this pattern consistently transitions into an area of sliding, which represents the physical limit of pneumothorax as mapped on the chest wall" [3]. It is $100 \%$ specific for partial pneumothorax [18, 19], and represents the location where visceral and parietal pleurae part company. Animal and human studies suggest that the position of lung point in relation to the mid-axillary line correlates with pneumothorax size $[20,21]$. Lung point is not seen in complete pneumothorax, when no lung is in contact with parietal pleura.

Ultrasound for pneumothorax is more challenging with inexperienced operators or small loculated pneumothoraces, and is impeded by subcutaneous emphysema or chest wall bandaging [20, 22-26].

The accuracy of ultrasound for pneumothorax diagnosis has been compared to chest radiography (table 2) in four meta-analyses [24, 27-29]. Pooled ultrasound sensitivity was $78-90 \%$ and pooled specificity was $>98 \%[24,27-29]$. Chest radiography had a poorer pooled sensitivity of $39-52 \%$, but a similar pooled specificity [24, 25, 27]. Important caveats apply. First, the populations studied were mainly trauma and critically ill patients, or those who had undergone percutaneous thoracic procedures. Thus, the results may not be applicable to patients presenting with suspected spontaneous pneumothorax, particularly those with underlying COPD [14]. Secondly, the prevalence of pneumothorax in the reviews was between 13 and $30 \%$, reflecting the highly selected study population. Many studies also excluded patients in whom ultrasound was not technically possible. Thirdly, the chest radiograph comparator was generally a supine film, which is poorly sensitive for pneumothorax.

Substantial heterogeneity was present among all four meta-analyses, possibly due to operator performance [24]. Also, some reviews meta-analysed by patient and others by hemithorax. We have previously found that using different units of analysis can give very different test characteristics [32].

TABLE 1 Chest ultrasound syndromes: typical sonographic findings and relevant differential diagnoses

Chest ultrasound syndrome

\section{Pleural}

Pneumothorax

Pleural effusion

\section{Parenchymal}

Consolidation

Interstitial syndrome

\section{Musculoskeletal}

Chest wall applications

Diaphragm applications
Sonographic features

Differential diagnosis
Absent lung sliding

Absent B-lines

Lung point (specific for pneumothorax)

Echo-free space

Quad sign (fluid-colour and sinusoid signs more specific for effusionl

Tissue-like pattern (iso- or hypo-echoic) Echogenic air-bronchograms B-lines

Pneumonia, atelectasis, neoplasm, pulmonary infarct

Diffuse: cardiogenic pulmonary oedema, non-cardiogenic pulmonary oedema, interstitial lung disease Focal: pneumonia, focal fibrosis, pulmonary contusion, pulmonary infarction, lymphangitis

Interrupted parietal pleura and restricted pleural movement in the context of subpleural mass

Impaired thickening

Reduced excursion
Malignant chest wall invasion

Diaphragmatic paresis, extrinsic limitation of diaphragm 

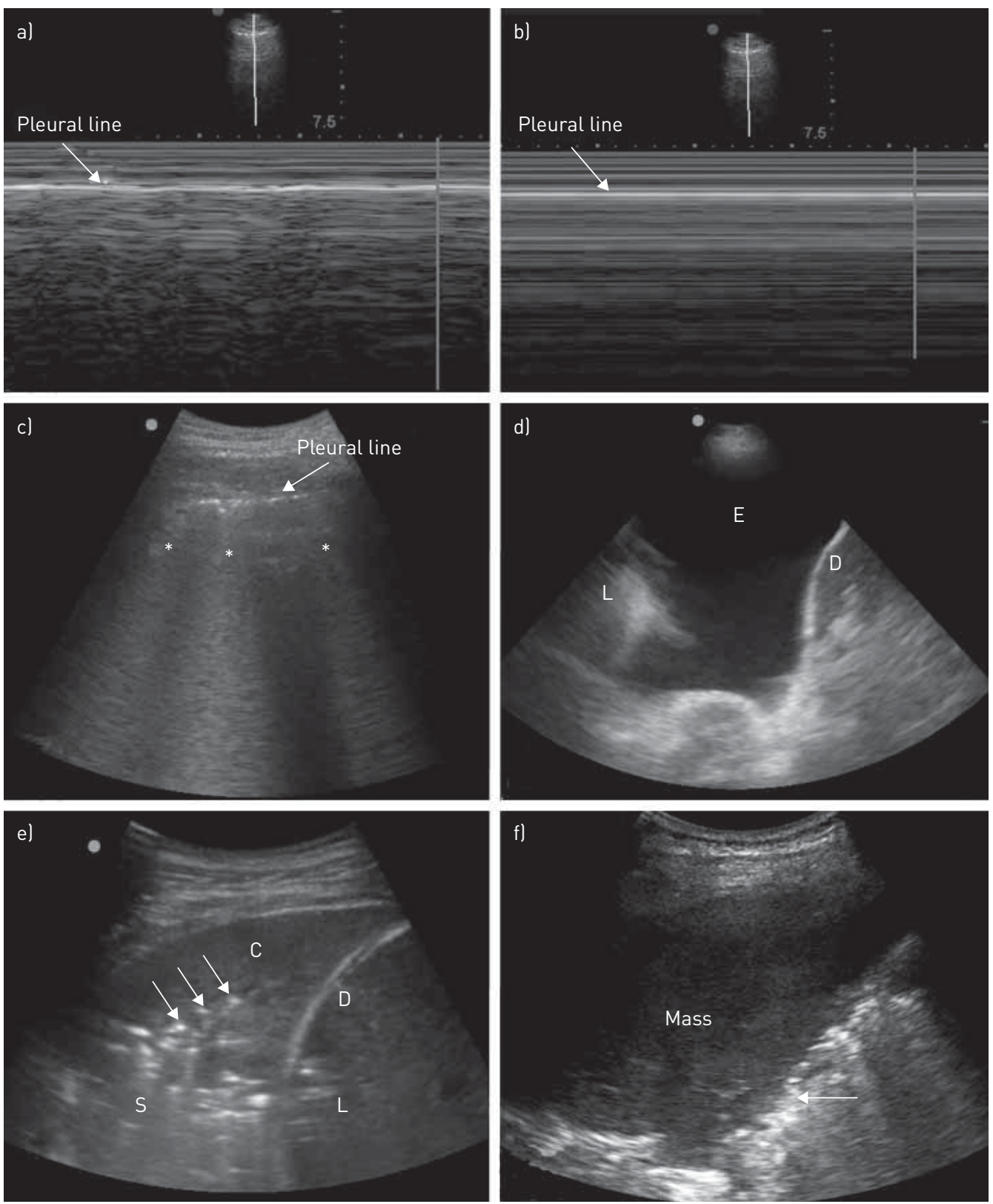

FIGURE 2 Selected chest ultrasound images. a) Sea-shore sign. Granular "sea-shore" appearance of normal lung sliding on M mode. b) Barcode sign. Horizontal "bar-code" appearance with loss of lung sliding on M mode. c) B-lines. Asterisks indicate comet tail artefacts arising from the pleural line (B-lines). d) Simple pleural effusion. " $E$ " indicates anechoic free-flowing effusion. " $L$ " indicates compressed atelectatic lung. " $D$ " indicates diaphragm. e) Consolidation. "C" indicates consolidation. " $D$ " indicates diaphragm. " $L$ " indicates liver. "S" indicates serrated distal margins of the consolidation. Arrows indicate air bronchograms. f) Lung tumour. The arrow indicates the smooth distal margin of the mass.

\section{Conclusion}

The evidence therefore suggests that ultrasound is superior to chest radiography in detecting pneumothorax among trauma, critically ill and post-procedural patients. These settings combine a high prevalence of traumatic pneumothorax with the immediate availability of trained sonographers, and the use of ultrasound as the initial test of choice is well supported. However, the accuracy of ultrasound for spontaneous pneumothorax is unclear and requires further study. Until more evidence has accrued in this area, we recommend that conventional radiology be used to diagnose spontaneous pneumothorax.

\section{Pleural effusion}

In pleural effusion, ultrasound is useful for diagnosis, prognosis and to guide therapeutic interventions. Ultrasound has been used to detect pleural effusion for more than 50 years (figure 2d) [33]. Simple effusions 


\begin{tabular}{|c|c|c|c|c|c|c|c|}
\hline & Number of studies & Population, unit of analysis & US features, comparator & Reference standard & Prevalence and number & Sensitivity & Specificity \\
\hline \multicolumn{8}{|l|}{ Pneumothorax } \\
\hline WILKERSON 2010 [25] & $\begin{array}{l}4 \text { studies } \\
\text { No meta-analysis }\end{array}$ & $\begin{array}{c}\text { Blunt trauma, } \\
\text { By patient ( } 3 \text { studies) } \\
\text { By hemithorax (1 study) }\end{array}$ & $\begin{array}{l}\text { Not stated } \\
\quad \text { CXR }\end{array}$ & $\begin{array}{l}\text { Chest } \mathrm{CT} \text { or } \\
\text { release of air }\end{array}$ & $\begin{array}{l}21.5-30.1 \% \text { of } 497 \text { patients } \\
11.5 \% \text { of } 218 \text { hemithoraces }\end{array}$ & $\begin{array}{l}\text { US: } 86-98 \% \\
\text { CXR: } 28-75 \%\end{array}$ & $\begin{array}{l}\text { US: } 97-100 \% \\
\text { CXR: } 100 \%\end{array}$ \\
\hline DING 2011 [24] & 20 studies & $\begin{array}{c}\text { Trauma, post-lung biopsy, } \\
\text { critically ill } \\
\text { By hemithorax }\end{array}$ & $\begin{array}{l}\text { Absent lung sliding, } \\
\text { absent comets, } \\
\text { lung point } \\
\text { CXR }\end{array}$ & $\begin{array}{l}\text { Chest CT or } \\
\text { clinical findings } \\
\text { and release of air }\end{array}$ & $\begin{array}{l}13.2 \% \text { of } 7569 \\
\text { hemithoraces }\end{array}$ & $\begin{array}{l}\text { US: } 88 \% \\
\text { CXR: } 52 \%\end{array}$ & $\begin{array}{l}\text { US: } 99 \% \\
\text { CXR: } 100 \%\end{array}$ \\
\hline ALRAJHI 2012 [27] & 8 studies & $\begin{array}{l}\text { Trauma, iatrogenic } \\
\text { By patient }{ }^{\#}\end{array}$ & $\begin{array}{l}\text { Absent lung sliding, } \\
\text { absent comets } \\
\text { CXR }\end{array}$ & $\begin{array}{l}\text { Chest } \mathrm{CT} \text { or } \\
\text { release of air }\end{array}$ & $\begin{array}{l}\text { Not stated } \\
\text { (unable to calculate) } \\
1048 \text { patients }\end{array}$ & $\begin{array}{l}\text { US: } 90.9 \% \\
\text { CXR: } 50.2 \%\end{array}$ & $\begin{array}{l}\text { US: } 98.2 \% \\
\text { CXR: } 99.4 \%\end{array}$ \\
\hline AlRAJAB 2013 [28] & 13 studies & $\begin{array}{l}\text { Trauma, post-lung biopsy, } \\
\text { critically ill } \\
\text { By hemithorax }\end{array}$ & $\begin{array}{l}\text { Not defined } \\
\quad \text { CXR }\end{array}$ & Chest CT & $\begin{array}{l}22.5 \% \text { of } 3028 \\
\text { hemithoraces }\end{array}$ & $\begin{array}{l}\text { US: } 78.6 \% \\
\text { CXR: } 39.8 \%\end{array}$ & $\begin{array}{l}\text { US: } 98.4 \% \\
\text { CXR: } 99.3 \%\end{array}$ \\
\hline EBRAHIMI 2014 [29] & 28 studies & $\begin{array}{c}\text { Trauma, iatrogenic, critically ill } \\
\text { By patient }\end{array}$ & $\begin{array}{l}\text { Not stated } \\
\quad \text { CXR }\end{array}$ & Chest CT & $20 \%$ of 5314 patients & $\begin{array}{l}\text { US: } 87 \% \\
\text { CXR: } 46 \%\end{array}$ & $\begin{array}{l}\text { US: } 99 \% \\
\text { CXR: } 100 \%\end{array}$ \\
\hline \multicolumn{8}{|l|}{ Pleural effusion } \\
\hline GRIMBERG 2010 [30] & 4 studies & $\begin{array}{c}\text { Trauma, heart failure, } \\
\text { ICU patients with ARDS } \\
\text { By patient }\end{array}$ & $\begin{array}{l}\text { Not stated } \\
\quad \text { CXR }\end{array}$ & $\mathrm{CT}$ or drainage & $27.6 \%$ of 924 patients & $\begin{array}{l}\text { US: } 92-96 \% \\
\text { CXR: } 24-100 \%\end{array}$ & $\begin{array}{l}\text { US: } 88-100 \% \\
\text { CXR: } 85-100 \%\end{array}$ \\
\hline YousEFIFARD 2016 [31] & 12 studies & $\begin{array}{c}\text { Trauma, heart failure, } \\
\text { critically ill, surgical patients } \\
\text { By patient }\end{array}$ & $\begin{array}{l}\text { Not stated } \\
\quad \text { CXR }\end{array}$ & $\mathrm{CT}, \mathrm{US}, \mathrm{CXR}$ & $41.5 \%$ of 1554 patients & $\begin{array}{l}\text { US: } 94 \% \\
\text { CXR: } 51 \%\end{array}$ & $\begin{array}{l}\text { US: } 98 \% \\
\text { CXR: } 91 \%\end{array}$ \\
\hline
\end{tabular}


on B-mode are anechoic $[34,35]$, bounded by parietal pleura above, visceral pleura below and rib shadows bilaterally (table 1). This is termed the "quad sign" [36]. The depth of the visceral pleura from the probe oscillates with the respiratory cycle, giving rise to the "sinusoid sign" on M-mode $[37,38]$. The presence of "fluid colour" on Doppler imaging due to pleural fluid movement is also characteristic $[39,40]$.

Ultrasound can characterise pleural effusion. While all transudates are anechoic (figure 2d), exudates may be either anechoic or echoic [41]. Visible internal echogenicity or stranding indicates an exudate [37]. Ultrasound may suggest the cause of pleural effusion. In an area where tuberculosis is uncommon, pleural thickening of $>1 \mathrm{~cm}$ or pleural nodularity predicted malignancy with a modest sensitivity, but a high degree of specificity [42]. Echogenic swirling also suggests malignancy [43]. Ultrasound can quantify pleural effusion, but measurements and formulae are only valid for free-flowing effusions [44, 45]. Ultrasound may predict the likelihood of successful pleural drainage. In one study, all anechoic para-pneumonic effusions were drained, whereas complex and septated effusions were successfully drained only half the time [46]. The movement and strain pattern of atelectatic lung in response to the cardiac impulse can also predict the presence of trapped lung [47].

With minimal training, novice operators can achieve a diagnostic accuracy for un-loculated effusions similar to expert operators [48]. With greater experience, respiratory physicians can be as accurate as radiologists at diagnosing pleural effusion, and have equally low complication rates for ultrasound-guided pleural interventions [49]. There are now validated instruments to assess an individual's skill at using ultrasound to guide pleural effusion drainage [50].

The accuracy of ultrasound for pleural effusion has been compared with that of chest radiography in two systematic reviews (table 2) [51, 52]. The earlier review included four studies and found that ultrasound had a sensitivity of $92-96 \%$, compared with a chest radiography sensitivity of $24-100 \%$ [51]. Ultrasound and chest radiography specificity were comparable at $88-100 \%$. The more recent review included 12 studies, and reported a pooled sensitivity of $94 \%$ and pooled specificity of $98 \%$ for ultrasound, compared with a pooled sensitivity of $51 \%$ and pooled specificity of $91 \%$ for chest radiography [52]. Both reviews comprised trauma, cardiac, critically ill (some with acute respiratory distress syndrome (ARDS)) and surgical cohorts, with a mean prevalence of $27-41 \%$ for pleural effusion. Not all studies used CT as a reference standard [52]. The morphology of pleural effusions (simple versus complex) in the included studies was not described.

\section{Conclusion}

The evidence suggests that ultrasound is superior to chest radiography for detecting pleural effusion in specific populations with suggestive clinical features. Where available, ultrasound is therefore a reasonable initial test for this indication.

\section{Lung consolidation}

In consolidation, the alveolar space fills with fluid. Key sonographic features are: loss of the bright pleural line; a real image as opposed to an artefact; a tissue-like pattern; echogenic air-bronchograms; hypoechoic vascular structures; and an irregular serrated distal border (figure 2e) [51, 52].

Consolidation is nonspecific (table 1). The many possible aetiologies include infectious pneumonia, organising pneumonia, pulmonary infarction and ARDS. However, some additional ultrasound features, when present, may suggest the underlying cause. Hypoechoic tubular fluid-bronchograms without flow signal on Doppler were found exclusively in obstructive pneumonia in one study [52]. Microabscesses in necrotising pneumonia are seen within consolidated lung as rounded hypoechoic or anechoic lesions with ill-defined margins [52]. Lung tumours causing obstructive consolidation appear as homogeneous nodules with well-defined margins (figure 2f) [52]. Dynamic air bronchograms differentiate pneumonic consolidation from resorptive atelectasis [53]. Pneumonic consolidation has more rapid and marked enhancement with sonographic contrast [54]. Consolidation may be difficult to detect when it is hidden behind bony structures [55] or does not extend to the pleura [56]. However, the latter is reportedly rare [51].

Other ultrasound features apart from consolidation have been described in patients with pneumonia. These include focal B-lines and pleural effusion [57]. In one study, anterior consolidation, anterior diffuse B-lines with abolished lung sliding, anterior asymmetric B-lines, and posterior consolidation or effusion without anterior diffuse B-lines were all suggestive of pneumonia [58].

Occlusion of a pulmonary artery may lead to pulmonary infarction, atelectasis and local pulmonary oedema [59, 60]. These pathophysiological changes are visible sonographically as wedge-shaped or rounded pleural-based consolidation [61,62], often in association with pleural effusion [61], and usually in posterior basal segments [63]. The use of Doppler and sonographic contrast to detect alterations in blood flow $[54,64]$ may differentiate pulmonary infarction from consolidation caused by other aetiologies. 
The diagnostic accuracy of ultrasound for lung consolidation has been examined in two ways. One approach has been to measure its accuracy to detect radiological consolidation. Another approach has been to measure its accuracy for specific disease entities which cause consolidation, chiefly pneumonia and pulmonary infarction.

A recent systematic review examined the accuracy of ultrasound for consolidation referenced to CT (table 3) [32]. This review focused on the imaging findings of consolidation rather than the underlying aetiology. The sensitivity of ultrasound was greater than chest radiography (91-100\% versus $38-68 \%$ ) while specificity was similar (78-100\% versus $89-95 \%)$. This review was restricted to hospitalised adults with respiratory failure who also underwent CT scanning. The risk of selection bias was high in the included studies, and clinician sonographers who were unblinded to clinical data may have inflated the sensitivity of ultrasound. All studies were set in intensive care and most patients were ventilated.

This systematic review included a study reporting two different units of analysis (the unit of analysis is a statistical term denoting the major entity analysed in a study) [70]. The use of lung region (12 regions per patient) instead of lung (two lungs per patient) as the unit of analysis decreased sensitivity, increased specificity, inflated the sample size and gave the misleading impression of greater precision. The review concluded that studies reporting different units of analysis should not be meta-analysed together, even though this is sometimes attempted. We therefore suggest that primary studies should report individual patients as the unit of analysis even when findings are acquired by lung or lung region. This will facilitate future comparisons between studies or pooling of results.

\section{Conclusion for detection of consolidation}

Therefore, based on a small body of evidence at high risk of selection and index test bias, ultrasound is more sensitive than chest radiography for consolidation in adults in intensive care with acute respiratory failure. It would appear reasonable to deploy ultrasound as the initial testing modality in this scenario. It is important to bear in mind that ultrasound sensitivity may be lower for less unwell patients in other settings, because they may have less extensive consolidation.

With the second approach of measuring the accuracy of ultrasound for a specific consolidative aetiology, three reviews suggest ultrasound is sensitive (94-97\%) and specific (90-96\%) for pneumonia in adults. One review also included children and neonates (table 3) [65-67]. The most recent review found that ultrasound had greater sensitivity compared with chest radiography (90\% versus $77 \%$ ) [67].

A number of caveats apply. First, the high prevalence of pneumonia in all three meta-analyses implies a highly selected population. Secondly, ultrasound features used to diagnose pneumonia comprised a combination of alveolar consolidation and interstitial changes. However, there are a wide range of other pathologies that may cause identical sonographic findings (table 1). Thirdly, the reference standards of included studies ranged from clinical diagnosis (of doubtful reliability), through to chest radiography (of limited sensitivity), and CT (in the minority). A number of studies were at risk of differential verification bias, because not all patients underwent the same reference testing.

There is also an inherent limitation in using ultrasound to "diagnose" pneumonia. In reality, ultrasound only detects imaging findings [32]. Clinician input is required to integrate imaging findings with clinical data to make the clinical diagnosis of pneumonia. (This limitation applies to all imaging modalities, not just ultrasound, and ideally all imaging research should report detection rates of imaging abnormalities, not of clinical diagnoses.) Therefore research studies examining the accuracy of ultrasound to diagnose pneumonia are compelled to incorporate a clinician interpretation into reported test characteristics. This interpretation is influenced by the prevalence of pneumonia relative to other causes of sonographic abnormalities in the test population. In the three meta-analyses cited, the prevalence of pneumonia was $50-67 \%$. In settings with a lower prevalence of pneumonia, the probability of ultrasound detecting changes due to a different disease would be correspondingly higher, reducing the specificity for pneumonia.

\section{Conclusion for diagnosis of pneumonia}

It therefore appears, from an evidence base at significant risk of selection and verification bias, that ultrasound is highly sensitive and specific for pneumonia. However, this may only apply when the suspicion of pneumonia is high and other pathology is unlikely, limiting the applicability of reported test performance to other settings.

Finally, two meta-analyses have also examined the accuracy of ultrasound for pulmonary embolism. The included studies mainly detected pleural-based consolidation suggestive of pulmonary infarction (table 3 ) $[68,69]$. No included studies used Doppler or ultrasound contrast to differentiate infarction from other causes of consolidation. Sensitivity and specificity were between $85-87 \%$ and $81.8-83 \%$, respectively, but 


\begin{tabular}{|c|c|c|c|c|c|c|c|}
\hline & Number of studies & Population, unit of analysis & US features, comparator & Reference standard & Prevalence and number & Sensitivity & Specificity \\
\hline \multicolumn{8}{|l|}{ Consolidation } \\
\hline Hew 2015 [32] & $\begin{array}{c}4 \text { studies } \\
\text { No meta-analysis }\end{array}$ & $\begin{array}{c}\text { Hospitalised adults with } \\
\text { acute respiratory failure, } \\
\text { By patient, lung or lung } \\
\text { region }\end{array}$ & $\begin{array}{l}\text { Consolidation } \\
\text { CXR }\end{array}$ & CT only & $\begin{array}{l}\text { Unable to summarise } \\
\text { prevalence from } \\
\text { heterogeneous units of } \\
\text { analysis } \\
224 \text { patients }\end{array}$ & $\begin{array}{l}\text { US: } 98-100 \% \\
\text { CXR: } 38-68 \%\end{array}$ & $\begin{array}{l}\text { US: } 78-100 \% \\
\text { CXR: } 89-95 \%\end{array}$ \\
\hline \multicolumn{8}{|l|}{ Pneumonia } \\
\hline Hu 2014 [65] & 9 studies & $\begin{array}{c}\text { Included adults, children, } \\
\text { neonates } \\
\text { By patient }\end{array}$ & Unstated & $\begin{array}{l}\text { CXR/CT, or CXR only, or } \\
\text { clinical diagnoses }\end{array}$ & $62.5 \%$ of 1080 patients & US: $97 \%$ & US: $94 \%$ \\
\hline Chavez 2014 [66] & 10 studies & $\begin{array}{c}\text { Adults with clinical suspicion } \\
\text { of pneumonia, or acute } \\
\text { respiratory failure } \\
\text { By patient, lung, or lung } \\
\text { region }{ }^{\#}\end{array}$ & $\begin{array}{l}\text { Consolidation or } \\
\text { "alveolar } \\
\text { and interstitial" }\end{array}$ & $\begin{array}{c}\text { CT only, or CXR or } \mathrm{CT} \text {, or } \\
\text { clinical diagnosis/ } \\
\text { CT/CXR }\end{array}$ & $\begin{array}{c}\text { Calculated at } 50 \% \text { of } 1098 \\
\text { patients in studies analysed } \\
\text { by patient }\end{array}$ & US: $94 \%$ & US: $96 \%$ \\
\hline YE 2015 [67] & 5 studies & $\begin{array}{c}\text { Clinically suspected } \\
\text { pneumonia in adults } \\
\text { By patient }\end{array}$ & $\begin{array}{l}\text { Uni/bilateral or focal } \\
\text { alveolar-interstitial } \\
\text { syndrome, } \\
\text { or consolidation with } \\
\text { air bronchograms }\end{array}$ & $\begin{array}{l}\text { Hospital discharge } \\
\text { diagnosis }\end{array}$ & $67.3 \%$ of 742 patients & $\begin{array}{l}\text { US: } 95 \% \\
\text { CXR: } 77 \%\end{array}$ & $\begin{array}{l}\text { US: } 90 \% \\
\text { CXR: } 91 \%\end{array}$ \\
\hline \multicolumn{8}{|l|}{ Pulmonary embolism } \\
\hline Squizzato 2013 [68] & 10 studies & $\begin{array}{c}\text { Clinical suspicion of } \mathrm{PE} \\
\text { By patient }\end{array}$ & $\begin{array}{l}5 \text { studies: round or } \\
\text { wedge-shaped lesions } \\
5 \text { studies: not reported }\end{array}$ & $\begin{array}{c}6 \text { studies: composite } \\
4 \text { studies: CTPA or } V^{\prime} / Q^{\prime} \\
\text { or MRA }\end{array}$ & $61 \%$ of 887 patients & $87 \%$ & $81.8 \%$ \\
\hline JIANG 2015 [69] & 13 studies & $\begin{array}{c}\text { Adults with suspected PE } \\
\text { By patient }\end{array}$ & $\begin{array}{l}7 \text { studies: round or } \\
\text { wedge-shaped lesions } \\
6 \text { studies: not reported }\end{array}$ & $\begin{array}{c}8 \text { studies: composite } \\
5 \text { studies: CTPA or } V^{\prime} / Q^{\prime} \\
\text { or MRA }\end{array}$ & $50.6 \%$ & $85 \%$ & $83 \%$ \\
\hline
\end{tabular}


when results were summarised only from studies of higher quality, sensitivity and specificity fell to $77 \%$ and $75 \%$, respectively [68].

Patient selection presented a high risk of bias or applicability concerns in many included studies. This concern was supported by the very high prevalence (50-61\%) of pulmonary embolus, which is threefold higher than the prevalence of pulmonary embolus in studies of patients undergoing CT pulmonary angiogram (CTPA) [71-73].

The difficulties regarding the use of ultrasound imaging to "diagnose" the clinical condition of pneumonia also apply to pulmonary embolus. Small peripheral areas of consolidation may be due to causes other than pulmonary infarction. In settings where the probability of pulmonary embolus is lower, the likelihood of an alternative explanation for sonographic consolidation will increase.

CTPA remains the gold standard for diagnosis of pulmonary embolism, but involves radiation and intravenous contrast. It has been suggested that chest ultrasound might be employed as a screening test prior to CTPA $[63,74]$, but this strategy has not been tested prospectively.

Chest ultrasound combined with targeted cardiac echocardiography and lower limb vein ultrasound increases the sensitivity and specificity for pulmonary embolus to $90 \%$ and $86.2 \%$, respectively [63]. This may be a good option in patients unable to undergo CTPA.

\section{Conclusion for diagnosis of pulmonary embolus}

The evidence therefore suggests that in settings with an extremely high probability of pulmonary embolus, chest ultrasound has modest sensitivity and specificity for pulmonary embolus. These test characteristics are inferior to CTPA, which therefore remains the test of choice. In patients unsuitable for CTPA, it appears reasonable to proceed with the combination of cardiac, chest and peripheral venous ultrasound.

\section{The interstitial syndrome}

There is a clear relationship between B-lines (defined earlier) and the interstitial syndrome [75]. B-lines are probably formed by the reverberation of ultrasound waves between thickened interstitial septa just below the pleura. A scanning region is considered positive when three or more B-lines are visible within a rib space, and the ultrasound examination is considered positive for the interstitial syndrome when two or more regions are positive bilaterally [3]. Multiple B-lines can also be found in healthy individuals in the lowest intercostal spaces posteriorly. There is no consensus regarding how B-lines should be counted [76, 77]. Some groups have utilised automated B-line counting, but this cannot yet be performed in real-time [78].

Increased B-lines may be focal or diffuse (table 1). Pneumonia [57, 58, 79], pulmonary contusion [80] or focal fibrosis cause focal B-lines. Increased lung water or diffuse fibrotic conditions cause diffuse B-lines [81].

Ultrasound predicts the volume of extravascular lung water [82]. There is a linear relationship between the total number of B-lines and lung weight estimated using CT [83]. One study used whole lung lavage to correlate sonographic imaging to lung water [84]. Increasing lung water was represented initially by B-lines, then as "white lung" formed by coalescent B-lines, and ultimately as alveolar consolidation.

Non-cardiogenic pulmonary oedema (ARDS) is one important cause of increased lung water that causes pathological B-lines. The ultrasound-derived lung oedema score reflects sepsis-induced acute lung injury and correlates with sepsis severity [85]. Lung recruitment and re-aeration by the application of positive end-expiratory pressure can be demonstrated by the transformation of consolidation into B-lines, or the disappearance of B-lines [79]. Chest ultrasound may also guide fluid resuscitation in critically ill patients [86].

Cardiogenic pulmonary oedema also increases B-lines. However, ultrasound does not accurately predict pulmonary artery occlusion pressure (PAOP) $[82,87]$. The absence of B-lines had a specificity of $95 \%$, but a sensitivity of only $50 \%$ to predict PAOP $\leqslant 18 \mathrm{mmHg}$ [88]. This is not surprising, since the interstitial syndrome is not specific to cardiogenic pulmonary oedema.

The differentiation of cardiogenic pulmonary oedema from ARDS therefore requires other supportive findings. Compared to patients with cardiogenic pulmonary oedema, patients with ARDS may more often have: areas without B-lines on the anterior chest, increased posterior consolidation, an irregular and thickened pleural line, and reduced pleural lung sliding [89]. However, substantial overlap remains and further work-up may be needed to distinguish the two.

Patients with pulmonary fibrosis also have diffusely increased B-lines [90], which correlate to the severity of fibrosis on high-resolution CT imaging [91]. Ultrasound may be used to screen for pulmonary fibrosis in patients with systemic sclerosis [92]. Other ultrasound features such as pleural thickening and subpleural nodules have been reported in patients with connective tissue disease-associated fibrosis [93]. 
TABLE 4 Diagnostic accuracy of ultrasound (US) in the interstitial syndrome: evidence from systematic reviews

\begin{tabular}{|c|c|c|c|c|c|c|c|}
\hline & $\begin{array}{l}\text { Number } \\
\text { of studies }\end{array}$ & $\begin{array}{l}\text { Population, } \\
\text { unit of analysis }\end{array}$ & US features & $\begin{array}{l}\text { Reference } \\
\text { standard }\end{array}$ & $\begin{array}{l}\text { Prevalence } \\
\text { and number }\end{array}$ & Sensitivity & Specificity \\
\hline \multicolumn{8}{|l|}{$\begin{array}{l}\text { Acute cardiogenic } \\
\text { pulmonary oedema }\end{array}$} \\
\hline Al Deeb 2014 [94] & 7 studies & $\begin{array}{c}\text { Patients presenting } \\
\text { with } \\
\text { undifferentiated } \\
\text { dyspnoea } \\
\text { By patient }\end{array}$ & $\begin{array}{l}\text { US criteria not } \\
\text { restricted as } \\
\text { long as B-lines } \\
\text { were used }\end{array}$ & $\begin{array}{c}5 \text { studies: blinded } \\
\text { chart review } \\
2 \text { studies: } \\
\text { final diagnosis }\end{array}$ & $\begin{array}{l}45 \% \text { of } 1075 \\
\text { patients }\end{array}$ & $94.1 \%$ & $92.4 \%$ \\
\hline MARTINDALE 2016 [95] & 8 studies & $\begin{array}{c}\text { Adults presenting to } \\
\text { ED with dyspnoea } \\
\text { By patient }\end{array}$ & $\begin{array}{c}\text { At least } 3 \\
\text { B-lines in each } \\
\text { lung } \\
\text { Performed by } \\
\text { emergency } \\
\text { specialists }\end{array}$ & $\begin{array}{l}\text { Clinical diagnosis } \\
\text { by independent } \\
\text { reviewers blinded } \\
\text { to index test result }\end{array}$ & $\begin{array}{c}45.6 \% \text { of } \\
1914 \text { patients }\end{array}$ & $85.3 \%$ & $92.7 \%$ \\
\hline
\end{tabular}

ED: emergency department.

Systematic reviews and meta-analyses have examined the diagnostic accuracy of ultrasound for acute cardiogenic pulmonary oedema. Two systematic reviews found that the sensitivity of increased B-lines for acute cardiogenic pulmonary oedema was $85-94 \%$, while specificity was $92-93 \%$ (table 4 ) [94, 95].

One review also summarised the diagnostic accuracy of other tests for acute heart failure: history, examination, ECG, chest radiography, brain natriuretic peptide (BNP) and pro-BNP, echocardiography and bio-impedance [95]. Lung ultrasound had the highest positive likelihood ratio (7.1) and the second lowest negative likelihood ratio (0.16), after BNP and pro-BNP (0.09-0.11).

Both reviews included studies examining patients with acute breathlessness. Different studies used differing methods of B-line counting. Almost all studies used clinical impression as the reference standard for heart failure diagnosis. In both reviews, the prevalence of acute heart failure was very high at $45 \%$. In contrast, in an intensive care study where pneumonia was more prevalent than cardiogenic pulmonary oedema, the presence of B-lines was neither sensitive nor specific for pulmonary oedema [96].

Conclusion for the diagnosis of cardiogenic pulmonary oedema

The evidence therefore suggests that in patients presenting to emergency departments with breathlessness and a high pre-test probability for acute cardiogenic pulmonary oedema, increased B-lines are highly sensitive and specific for this diagnosis. In settings where alternative causes for B-lines are more likely, the specificity of ultrasound is lower. The best method for B-line counting remains to be determined. The combination of lung ultrasound with other tests such as BNP and echocardiography increases diagnostic accuracy, and in our view forms the optimal diagnostic approach.

\section{Chest wall abnormalities}

Chest wall invasion by lung cancer may be suggested by absent lung sliding, interruption of the pleural reflection, visible tumour growth into the chest wall, and rib invasion [97, 98]. Using intraoperative findings and final pathology as the reference standard, ultrasound had superior diagnostic accuracy for invasion compared with CT, with a sensitivity and specificity of $89-100 \%$ and $95-98 \%$, respectively, whereas CT had a sensitivity and specificity of $42-68 \%$ and $66-100 \%$, respectively $[98,99]$.

Ultrasound may identify unprotected intercostal arteries vulnerable to percutaneous pleural interventions [100]. SALAMONSEN et al. [101] visualised intercostal arteries using colour Doppler and confirmed significant variation in their course. In a subsequently contrast CT-validated study, ultrasound had excellent sensitivity (86\%) but poor specificity (30\%) for detecting such vulnerable intercostal vessels [102]. Further refinements are needed to improve the specificity of this technique and define its clinical utility [103].

\section{Diaphragm abnormalities}

Diaphragm excursion and thickness are both readily identified on ultrasound and can be used to assess diaphragm function.

Diaphragm excursion can be measured on $\mathrm{M}$ mode by visualising the dome of each hemi-diaphragm via the anterior subcostal approach [104, 105]. Diaphragm thickness is measured laterally at the zone of 
apposition at the lower intercostal spaces [106]. The diaphragm thickening fraction is calculated as (end-inspiratory thickness minus end-expiratory thickness)/end-inspiratory thickness and has been used to assess diaphragm activity $[107,108]$.

Ultrasound has been used to detect diaphragm dysfunction in small cohorts of ventilated patients [109, 110]. Diaphragmatic excursion of $<1 \mathrm{~cm}$ had a sensitivity and specificity of $83 \%$ and $41 \%$, respectively, for predicting weaning failure from mechanical ventilation [111]. Diaphragm thickening has also been correlated with the work of breathing in ventilated patients and may be used to predict weaning failure [112]. In a small prospective study, a diaphragm thickening fraction $>36 \%$ predicted a successful spontaneous breathing trial with a sensitivity of $82 \%$ and a specificity of $88 \%$ [108]. These preliminary findings compare favourably with current weaning indices, but warrant further study in larger well-defined cohorts. We suggest that until more data becomes available, clinical decisions regarding the timing of extubation should not be based on ultrasound indices alone.

\section{Impact on clinician decision-making: diagnostic thinking and therapeutic efficacy}

Many of the studies examining the influence of chest ultrasound on medical decision-making have been conducted in critically ill patients with acute respiratory failure or dyspnoeic patients in the emergency department.

\section{Acute respiratory failure}

A series of studies over the past decade have demonstrated diagnostic thinking efficacy for chest ultrasound in acute respiratory failure. Lichtenstein and Mezière [58] performed chest and leg vein ultrasound in ventilated patients on intensive care unit admission. Ultrasound correctly identified the underlying condition (pneumonia, cardiogenic pulmonary oedema, pneumothorax, COPD and pulmonary embolus) in $90 \%$. In a cohort with similar causes of acute respiratory failure, Silva et al. [113] compared a protocol of cardiac, chest and leg vein ultrasound to no ultrasound. Most patients received either invasive or noninvasive ventilation. Sonography increased diagnostic accuracy from $63 \%$ to $83 \%$. Finally, BATAILLE et al. [96] showed that echocardiography combined with chest ultrasound had superior diagnostic accuracy to chest ultrasound alone ( $81 \%$ versus $63 \%)$.

Some caveats apply. First, patients with multiple pathologies (4-5\%) were excluded from all studies, although the number excluded from the third study was not reported. The earliest study also excluded patients with rare or unclear diagnoses. If accuracy is recalculated without these exclusions, diagnostic accuracy drops to $78 \%$ and $79 \%$ respectively for the first two studies. Secondly, none of the three studies reported ARDS as a cause of respiratory failure. However, in other series, sepsis and ARDS were important causes of acute respiratory failure [114]. In a recent report, ARDS caused $67 \%$ of acute respiratory failure in patients with pulmonary infiltrates [115]. Importantly the ultrasound features of ARDS overlap with pneumonia and cardiogenic pulmonary oedema [89, 116]. Therefore, in cohorts that include ARDS, ultrasound is probably less discriminating. Thirdly, chest ultrasound in all studies was coupled to either echocardiography, leg vein ultrasound or both. Only one study reported the yield of chest ultrasound as a single modality (63\%), and this was not compared to the diagnostic accuracy of clinical diagnosis without ultrasound [96]. Finally, the reference standard in all studies was expert clinical diagnosis. Based on autopsy series however, the clinical diagnosis in critically ill patients may be inaccurate in 20 $30 \%$ of cases $[117,118]$.

Overall, the evidence does suggests that the early use of chest ultrasound can help diagnose the cause of acute respiratory failure, particularly when supplemented by cardiac and leg vein ultrasound. In our view, it is reasonable to perform such a multisystem ultrasound survey when such expertise is available. However, the presence of either ARDS or multiple pathologies is likely to lower the diagnostic yield.

It also appears that the use of ultrasound in acute respiratory failure can change patient management of patients already in intensive care. XIROUCHAKI et al. [119] reported that the use of chest ultrasound changed management in $47 \%$ of critically ill patients with unexplained worsening hypoxia, or the suspicion of pneumothorax, atelectasis, pneumonia, pleural effusion or pulmonary oedema. In this study, ultrasound was employed to answer specific clinical questions. Notably, all but one of 253 scans demonstrated consolidation, effusion or interstitial syndrome. From this, the authors concluded that indiscriminate use of ultrasound would not have been as useful as their selective approach.

\section{Acute breathlessness}

Chest ultrasound may also influence medical decision-making in the emergency department. In a small series of patients presenting with acute dyspnoea, the use of chest ultrasound changed the diagnosis in $44 \%$ and altered management in 58\% [120]. 
More recently, a RCT by LAURSEN et al. [121] found the use of combined cardiac, lung and deep vein ultrasound in patients presenting to the emergency department with breathlessness, desaturation, chest pain or cough increased the rate of correct initial diagnosis within $4 \mathrm{~h}$ from $67 \%$ to $88 \%$. Consequently, appropriate treatment was commenced within $4 \mathrm{~h}$ in more patients undergoing ultrasound (78\% versus 56\%).

In this single-centre trial, all scans were performed by one experienced sonographer within an hour of admission to the medical emergency ward. Only patients admitted during his shifts were eligible for screening, and more than $50 \%$ of those screened did not meet inclusion. No differences were found in terms of length of stay or mortality, but this trial was not powered to detect changes in such outcomes. Despite these caveats, the results suggest that early multisystem sonography (including chest ultrasound) is effective in achieving rapid diagnosis and appropriate management of this patient group.

\section{Impact on health outcomes: patient outcome and societal efficacy}

Robust evidence for patient and societal benefit can be found for ultrasound-guided pleural interventions. However, there is a paucity of evidence for outcome efficacy of chest ultrasound in relation to parenchymal lung disorders and musculoskeletal conditions.

A systematic review from 2010 concluded that the use of ultrasound to guide pleural aspiration reduced the risk of pneumothorax with an odds ratio of 0.3 [122]. The meta-analysis included data from 22 observational studies and two randomised trials. Only one of the two trials was positive. The negative trial used remote guidance rather than immediate guidance, with ultrasound marking being performed in radiology but aspiration taking place on the ward [123]. A more recent trial also found that ultrasound reduced the risk of pneumothorax from $12 \%$ to $1 \%$ and increased the likelihood of aspirating fluid [124].

A second meta-analysis confined to pleural aspiration in mechanically ventilated patients also found that ultrasound use reduced the odds for pneumothorax (OR 0.3 ), but this was not statistically significant perhaps due to the small number of studies [125]. Observational studies using insurance databases have confirmed a reduction in pneumothorax and haemorrhagic complications with ultrasound guidance [126, 127].

On the basis of evidence for patient outcome efficacy, ultrasound guidance for drainage of pleural effusion is now the recommended standard of care [128], although uptake remains incomplete in some areas of medical practice $[129,130]$.

Based on decision-tree analysis, ultrasound-guided pleural aspiration is cost-effective, mainly due to a reduction in pneumothorax rates [131, 132]. This has been confirmed in the database studies mentioned above, with a $6 \%$ reduction in total hospitalisation cost $[126,127]$. In addition, if radiology-performed ultrasound guidance is substantial delayed, clinician-performed ultrasound guidance provides further cost-benefit [132].

\section{The future}

Our review has highlighted the impressive reported accuracy of ultrasound for a number of conditions. However, substantial gaps are present in the current evidence (figure 3). We have shown that evidence for efficacy is greatest in pleural ultrasound, where there is an impact on health outcomes. There is less evidence for health outcome efficacy in parenchymal lung ultrasound, although it clearly influences clinical decision making. There is least evidence for efficacy in musculoskeletal chest ultrasound, with data generally limited to

\begin{tabular}{|c|c|c|c|c|c|c|c|}
\hline \multicolumn{2}{|c|}{ Levels of efficacy } & \multicolumn{2}{|c|}{$\begin{array}{c}\text { Pleural } \\
\text { syndromes }\end{array}$} & \multicolumn{2}{|c|}{$\begin{array}{l}\text { Parenchymal } \\
\text { syndromes }\end{array}$} & \multicolumn{2}{|c|}{$\begin{array}{l}\text { Musculoskeletal } \\
\text { syndromes }\end{array}$} \\
\hline & & \multirow[t]{2}{*}{$\begin{array}{l}\text { Pleural } \\
\text { effusion }\end{array}$} & \multirow[t]{2}{*}{ Pneumothorax } & \multirow[t]{2}{*}{ Consolidation } & \multirow[t]{2}{*}{$\begin{array}{l}\text { Interstitial } \\
\text { syndrome }\end{array}$} & \multirow[t]{2}{*}{$\begin{array}{c}\text { Chest wall } \\
\text { abnormalities }\end{array}$} & \multirow[t]{2}{*}{$\begin{array}{c}\text { Diaphragm } \\
\text { abnormalities }\end{array}$} \\
\hline $\begin{array}{l}\text { Test } \\
\text { attributes }\end{array}$ & $\begin{array}{l}\text { 1) Technical } \\
\text { efficacy }\end{array}$ & & & & & & \\
\hline & $\begin{array}{l}\text { 2) Diagnostic } \\
\text { accuracy efficacy }\end{array}$ & & & & & & \\
\hline \multirow[t]{2}{*}{$\begin{array}{l}\text { Decision- } \\
\text { making }\end{array}$} & $\begin{array}{l}\text { 3) Diagnostic } \\
\text { thinking efficacy }\end{array}$ & & & & & & \\
\hline & $\begin{array}{l}\text { 4) Therapeutic } \\
\text { efficacy }\end{array}$ & & & & & & \\
\hline \multirow[t]{2}{*}{$\begin{array}{l}\text { Health } \\
\text { outcome }\end{array}$} & $\begin{array}{l}\text { 5) Patient outcome } \\
\text { efficacy }\end{array}$ & & & & & & \\
\hline & 6) Societal efficacy & & & & & & \\
\hline
\end{tabular}

FIGURE 3 Chest ultrasound syndromes: available evidence at each level of efficacy. Grey shading indicates a substantial body of evidence for that level of efficacy. 
the diagnostic accuracy for some conditions. Studies of diagnostic accuracy require extension to new settings; for example, is ultrasound as accurate for spontaneous pneumothorax as it is for traumatic pneumothorax?

There should be greater emphasis on measuring comparative accuracy [133]. In some scenarios, chest ultrasound offers compelling advantages over other tests, as it does not require ionising radiation (in pregnancy and paediatrics), intravenous contrast (in renal impairment or contrast allergy) or transport to the radiology department (in patients requiring complex organ support). However, the real challenge is to examine to what degree ultrasound is superior to current diagnostics in patients without these specific characteristics.

Accuracy studies should also evaluate chest ultrasound embedded within diagnostic pathways or test combinations, rather than as an isolated modality $[134,135]$. The intended role of chest ultrasound in such pathways should be explicitly defined, whether as an add-on test, replacement test or triage test since the desired performance characteristics differ for each [136]. In conducting such research, there is scope to enhance the quality of studies and systematic reviews by observing methodology guidelines [136-141].

Studies surrounding decision-making should ideally address the complexity of real-life clinical scenarios. To assist Bayesian diagnostic thinking and decision-making in complex patients, such as those with respiratory failure in intensive care, a positive or negative signal in one ultrasound domain (e.g. B-lines) may be coupled to signals in one or more other domains (e.g. consolidation or pleural effusion). Advanced statistical methods have already been employed to support such algorithms [96] and are likely to enter widespread use. This approach may be especially powerful when there is a specific clinical question to generate a pre-test probability for each differential diagnosis [119].

However, it is in health outcomes where the most research effort should be focused. It could be argued that the evident diagnostic accuracy of chest ultrasound obviates any need for demonstrating outcome efficacy. However, "evidence of test accuracy often provides low-quality evidence for making recommendations" [142], and confirmation of outcome efficacy provides a more robust basis for guidelines [143].

Despite the lack of ionising radiation, ultrasound is not risk-free. The greatest risk is of providing misleading results [144]. There are also opportunity costs consumed by sonographic training, capital investment and scarce bedside time with patients. The rise and fall of the pulmonary artery catheter offers a cautionary tale of a test implemented beyond its evidence base [145, 146]. Concerns regarding possible increased mortality have now limited its routine use, although it is still believed to have a role in specific instances.

While we support the increasing uptake of bedside chest ultrasound for indications with evidence for accuracy, we also believe there is a need for further research efforts to confirm that chest ultrasound improves hard outcomes (for applications other than guiding pleural interventions) [145].

In general, RCTs are the best study design to demonstrate patient outcome efficacy [11]. However, such studies are challenging to design and execute [147]. Consequently, very few tests have been shown to have patient outcome efficacy $[11,148]$. Successful trials require direct test-to-treatment coupling and measurable patient outcomes; for example, trials of ultrasound-guided pleural drainage (direct test-treatment coupling) to measure the rate of iatrogenic pneumothorax (immediate patient outcome) [122]. Selecting appropriate test-treatment couplings and immediate outcomes relevant to acute respiratory failure and other respiratory syndromes are therefore a high priority.

Because conducting RCTs in this area is so challenging, alternative methods of demonstrating patient outcome efficacy should also be explored. It may be possible to avoid a full-scale RCT by focusing on so-called "critical comparisons" between an existing diagnostic pathway and a new ultrasound pathway, and still allow the impact on patient outcomes to be modelled [131]. To design such studies, ultrasound researchers may need to collaborate closely with diagnostic test methodology experts.

In an era of cost-containment, there is also an increasing need to confirm societal efficacy for chest ultrasound, whether by RCTs, observational data, or robust economic analyses and modelling [134, 149, 150].

Finally, chest ultrasound has potential to change healthcare delivery. For example, the use of handheld ultrasound devices for suspected pleural effusion in a recent study removed the need for any further testing in $95 \%$ of cases [151]. Future implementation of such disruptive innovation may reconfigure the fundamental structure of health systems.

We believe advances in all these aspects of test efficacy will underpin the future of bedside chest ultrasound. 


\section{References}

1 Koenig SJ, Narasimhan M, Mayo PH. Thoracic ultrasonography for the pulmonary specialist. Chest 2011; 140: 1332-1341.

2 Hew M, Heinze S. Chest ultrasound in practice: a review of utility in the clinical setting. Intern Med J 2012; 42: 856-865.

3 Volpicelli G, Elbarbary M, Blaivas M, et al. International evidence-based recommendations for point-of-care lung ultrasound. Intensive Care Med 2012; 38: 577-591.

4 Platz E, Solomon SD. Point-of-care echocardiography in the accountable care organization era. Circ Cardiovasc Imaging 2012; 5: 676-682.

5 Bouhemad B, Zhang M, Lu Q, et al. Clinical review: bedside lung ultrasound in critical care practice. Crit Care 2007; 11: 205 .

6 Steinfort DP, Hew MJ, Irving LB. Bronchoscopic evaluation of the mediastinum using endobronchial ultrasound: a description of the first 216 cases carried out at an Australian tertiary hospital. Intern Med J 2011; 41: 815-824.

7 Ferrante di Ruffano L, Hyde CJ, McCaffery KJ, et al. Assessing the value of diagnostic tests: a framework for designing and evaluating trials. BMJ 2012; 344: e686.

8 Fryback DG, Thornbury JR. The efficacy of diagnostic imaging. Med Decis Making 1991; 11: 88-94.

9 Lijmer JG, Leeflang M, Bossuyt PM. Proposals for a phased evaluation of medical tests. Med Decis Making 2009; 29: E13-E21.

10 Staub LP, Lord SJ, Simes RJ, et al. Using patient management as a surrogate for patient health outcomes in diagnostic test evaluation. BMC Med Res Methodol 2012; 12: 12

11 National Lung Screening Trial Research Team, Aberle DR, Adams AM, et al. Reduced lung-cancer mortality with low-dose computed tomographic screening. N Engl J Med 2011; 365: 395-409.

12 Siontis KC, Siontis GC, Contopoulos-Ioannidis DG, et al. Diagnostic tests often fail to lead to changes in patient outcomes. J Clin Epidemiol 2014; 67: 612-621.

13 Lichtenstein DA, Menu Y. A bedside ultrasound sign ruling out pneumothorax in the critically ill. Lung sliding. Chest 1995; 108: 1345-1348.

14 Slater $\mathrm{A}$, Goodwin $\mathrm{M}$, Anderson KE, et al. COPD can mimic the appearance of pneumothorax on thoracic ultrasound. Chest 2006; 129: 545-550.

15 Zhang M, Liu ZH, Yang JX, et al. Rapid detection of pneumothorax by ultrasonography in patients with multiple trauma. Crit Care 2006; 10: R112.

16 Targhetta R, Bourgeois JM, Chavagneux R, et al. Ultrasonic signs of pneumothorax: preliminary work. J Clin Ultrasound 1993; 21: 245-250.

17 Lichtenstein D, Mezière G, Biderman P, et al. The comet-tail artifact: an ultrasound sign ruling out pneumothorax. Intensive Care Med 1999; 25: 383-388.

18 Lichtenstein D, Mezière G, Biderman P, et al. The "lung point": an ultrasound sign specific to pneumothorax. Intensive Care Med 2000; 26: 1434-1440.

19 Lichtenstein DA, Mezière G, Lascols N, et al. Ultrasound diagnosis of occult pneumothorax. Crit Care Med 2005 33: 1231-1238.

20 Volpicelli G, Boero E, Sverzellati N, et al. Semi-quantification of pneumothorax volume by lung ultrasound. Intensive Care Med 2014; 40: 1460-1467.

21 Oveland NP, Lossius HM, Wemmelund $\mathrm{K}$, et al. Using thoracic ultrasonography to accurately assess pneumothorax progression during positive pressure ventilation: a comparison with CT scanning. Chest 2013; 143: 415-422.

22 Abbasi S, Farsi D, Hafezimoghadam P, et al. Accuracy of emergency physician-performed ultrasound in detecting traumatic pneumothorax after a 2-h training course. Eur J Emerg Med 2013; 20: 173-177.

23 Hyacinthe AC, Broux C, Francony G, et al. Diagnostic accuracy of ultrasonography in the acute assessment of common thoracic lesions after trauma. Chest 2012; 141: 1177-1183.

24 Ding W, Shen Y, Yang J, et al. Diagnosis of pneumothorax by radiography and ultrasonography: a meta-analysis. Chest 2011; 140: 859-866.

25 Wilkerson RG, Stone MB. Sensitivity of bedside ultrasound and supine anteroposterior chest radiographs for the identification of pneumothorax after blunt trauma. Acad Emerg Med 2010; 17: 11-17.

26 Jalli R, Sefidbakht S, Jafari SH. Value of ultrasound in diagnosis of pneumothorax: a prospective study. Emerg Radiol 2013; 20: 131-134.

27 Alrajhi K, Woo MY, Vaillancourt C. Test characteristics of ultrasonography for the detection of pneumothorax: a systematic review and meta-analysis. Chest 2012; 141: 703-708.

28 Alrajab S, Youssef AM, Akkus NI, et al. Pleural ultrasonography versus chest radiography for the diagnosis of pneumothorax: review of the literature and meta-analysis. Crit Care 2013; 17: R208.

29 Ebrahimi A, Yousefifard M, Mohammad Kazemi H, et al. Diagnostic accuracy of chest ultrasonography versus chest radiography for identification of pneumothorax: a systematic review and meta-analysis. Tanaffos 2014; 13: 29-40.

30 Grimberg A, Shigueoka DC, Atallah AN, et al. Diagnostic accuracy of sonography for pleural effusion: systematic review. Sao Paulo Med J 2010; 128: 90-95.

31 Yousefifard M, Baikpour M, Ghelichkhani P, et al. Screening performance characteristic of ultrasonography and radiography in detection of pleural effusion; a meta-analysis. Emerg (Tehran) 2016; 4: 1-10.

32 Hew M, Corcoran JP, Harriss EK, et al. The diagnostic accuracy of chest ultrasound for CT-detected radiographic consolidation in hospitalised adults with acute respiratory failure: a systematic review. BMJ Open 2015; 5: e007838.

33 Joyner CR Jr, Herman RJ, Reid JM. Reflected ultrasound in the detection and localization of pleural effusion. JAMA 1967; 200: 399-402.

34 Laing FC, Filly RA. Problems in the application of ultrasonography for the evaluation of pleural opacities. Radiology 1978; 126: 211-214.

35 Rosenberg ER. Ultrasound in the assessment of pleural densities. Chest 1983; 84: 283-285.

36 Lichtenstein DA. Lung ultrasound in the critically ill. Ann Intensive Care 2014; 4: 1.

37 Marks WM, Filly RA, Callen PW. Real-time evaluation of pleural lesions: new observations regarding the probability of obtaining free fluid. Radiology 1982; 142: 163-164.

38 Lichtenstein D, Hulot JS, Rabiller A, et al. Feasibility and safety of ultrasound-aided thoracentesis in mechanically ventilated patients. Intensive Care Med 1999; 25: 955-958. 
Wu RG, Yang PC, Kuo SH, et al. "Fluid color" sign: a useful indicator for discrimination between pleural thickening and pleural effusion. J Ultrasound Med 1995; 14: 767-769.

Kalokairinou-Motogna M, Maratou K, Paianid I, et al. Application of color Doppler ultrasound in the study of small pleural effusion. Med Ultrason 2010; 12: 12-16.

Yang PC, Luh KT, Chang DB, et al. Value of sonography in determining the nature of pleural effusion: analysis of 320 cases. AJR Am J Roentgenol 1992; 159: 29-33.

Qureshi NR, Rahman NM, Gleeson FV. Thoracic ultrasound in the diagnosis of malignant pleural effusion. Thorax 2009; 64: 139-143.

Chian CF, Su WL, Soh LH, et al. Echogenic swirling pattern as a predictor of malignant pleural effusions in patients with malignancies. Chest 2004; 126: 129-134.

Roch A, Bojan M, Michelet $\mathrm{P}$, et al. Usefulness of ultrasonography in predicting pleural effusions $>500 \mathrm{~mL}$ in patients receiving mechanical ventilation. Chest 2005; 127: 224-232.

Balik M, Plasil P, Waldauf $\mathrm{P}$, et al. Ultrasound estimation of volume of pleural fluid in mechanically ventilated patients. Intensive Care Med 2006; 32: 318-321.

Chen $\mathrm{CH}$, Chen W, Chen HJ, et al. Transthoracic ultrasonography in predicting the outcome of small-bore catheter drainage in empyemas or complicated parapneumonic effusions. Ultrasound Med Biol 2009; 35: 1468-1474.

Salamonsen MR, Lo AK, Ng AC, et al. Novel use of pleural ultrasound can identify malignant entrapped lung prior to effusion drainage. Chest 2014; 146: 1286-1293.

Begot E, Grumann A, Duvoid T, et al. Ultrasonographic identification and semiquantitative assessment of unloculated pleural effusions in critically ill patients by residents after a focused training. Intensive Care Med 2014; 40: 1475-1480.

Rahman NM, Singanayagam A, Davies HE, et al. Diagnostic accuracy, safety and utilisation of respiratory physician-delivered thoracic ultrasound. Thorax 2010; 65: 449-453.

Salamonsen M, McGrath D, Steiler G, et al. A new instrument to assess physician skill at thoracic ultrasound, including pleural effusion markup. Chest 2013; 144: 930-934.

Lichtenstein DA, Lascols N, Mezière G, et al. Ultrasound diagnosis of alveolar consolidation in the critically ill. Intensive Care Med 2004; 30: 276-281.

Yang PC, Luh KT, Chang DB, et al. Ultrasonographic evaluation of pulmonary consolidation. Am Rev Respir Dis 1992; 146: 757-762.

Lichtenstein D, Mezière G, Seitz J. The dynamic air bronchogram. A lung ultrasound sign of alveolar consolidation ruling out atelectasis. Chest 2009; 135: 1421-1425.

Görg C, Bert T, Görg K. Contrast-enhanced sonography for differential diagnosis of pleurisy and focal pleural lesions of unknown cause. Chest 2005; 128: 3894-3899.

Nazerian P, Volpicelli G, Vanni S, et al. Accuracy of lung ultrasound for the diagnosis of consolidations when compared to chest computed tomography. Am J Emerg Med 2015; 33: 620-625.

Sperandeo M, Carnevale V, Muscarella S, et al. Clinical application of transthoracic ultrasonography in inpatients with pneumonia. Eur J Clin Invest 2011; 41: 1-7.

Parlamento S, Copetti R, Di Bartolomeo S. Evaluation of lung ultrasound for the diagnosis of pneumonia in the ED. Am J Emerg Med 2009; 27: 379-384.

Lichtenstein DA, Mezière GA. Relevance of lung ultrasound in the diagnosis of acute respiratory failure: the BLUE protocol. Chest 2008; 134: 117-125.

Reissig A, Kroegel C. Transthoracic ultrasound of lung and pleura in the diagnosis of pulmonary embolism: a novel non-invasive bedside approach. Respiration 2003; 70: 441-452.

Kroegel C, Reissig A. Principle mechanisms underlying venous thromboembolism: epidemiology, risk factors, pathophysiology and pathogenesis. Respiration 2003; 70: 7-30.

Reissig A, Heyne JP, Kroegel C. Sonography of lung and pleura in pulmonary embolism: sonomorphologic characterization and comparison with spiral CT scanning. Chest 2001; 120: 1977-1983.

Mathis G. Ultrasound diagnosis of pulmonary embolism. Eur J Ultrasound 1996; 3: 153-160.

Nazerian P, Vanni S, Volpicelli G, et al. Accuracy of point-of-care multiorgan ultrasonography for the diagnosis of pulmonary embolism. Chest 2014; 145: 950-957.

Yang PC. Color Doppler ultrasound of pulmonary consolidation. Eur J Ultrasound 1996; 3: 169-178.

Hu Q-J, Shen Y-C, Jia L-Q, et al. Diagnostic performance of lung ultrasound in the diagnosis of pneumonia: a bivariate meta-analysis. Int J Clin Exp Med 2014; 7: 115-121.

Chavez MA, Shams N, Ellington LE, et al. Lung ultrasound for the diagnosis of pneumonia in adults: a systematic review and meta-analysis. Respir Res 2014; 15: 50.

Ye X, Xiao H, Chen B, et al. Accuracy of lung ultrasonography versus chest radiography for the diagnosis of adult community-acquired pneumonia: review of the literature and meta-Analysis. PLoS One 2015; 10: 0130066. Squizzato A, Rancan E, Dentali F, et al. Diagnostic accuracy of lung ultrasound for pulmonary embolism: a systematic review and meta-analysis. J Thromb Haemost 2013; 11: 1269-1278.

Jiang L, Ma Y, Zhao C, et al. Role of transthoracic lung ultrasonography in the diagnosis of pulmonary embolism: a systematic review and meta-analysis. PLoS One 2015; 10: e0129909.

Xirouchaki N, Magkanas E, Vaporidi K, et al. Lung ultrasound in critically ill patients: comparison with bedside chest radiography. Intensive Care Med 2011; 37: 1488-1493.

Kline JA, Mitchell AM, Kabrhel C, et al. Clinical criteria to prevent unnecessary diagnostic testing in emergency department patients with suspected pulmonary embolism. J Thromb Haemost 2004; 2: 1247-1255.

Righini M, Le Gal G, Aujesky D, et al. Diagnosis of pulmonary embolism by multidetector CT alone or combined with venous ultrasonography of the leg: a randomised non-inferiority trial. Lancet 2008; 371: 1343-1352.

Perrier A, Roy PM, Aujesky D, et al. Diagnosing pulmonary embolism in outpatients with clinical assessment, D-dimer measurement, venous ultrasound, and helical computed tomography: a multicenter management study. Am J Med 2004; 116: 291-299.

Koenig S, Chandra S, Alaverdian A, et al. Ultrasound assessment of pulmonary embolism in patients receiving CT pulmonary angiography. Chest 2014; 145: 818-823.

75 Lichtenstein D, Mézière G, Biderman $\mathrm{P}$, et al. The comet-tail artifact. An ultrasound sign of alveolar-interstitial syndrome. Am J Respir Crit Care Med 1997; 156: 1640-1646. 
Anderson KL, Fields JM, Panebianco NL, et al. Inter-rater reliability of quantifying pleural B-lines using multiple counting methods. I Ultrasound Med 2013; 32: 115-120.

Gargani L, Frassi F, Soldati G, et al. Ultrasound lung comets for the differential diagnosis of acute cardiogenic dyspnoea: a comparison with natriuretic peptides. Eur J Heart Fail 2008; 10: 70-77.

Brattain LJ, Telfer BA, Liteplo AS, et al. Automated B-line scoring on thoracic sonography. J Ultrasound Med 2013; 32: 2185-2190.

Bouhemad B, Brisson $\mathrm{H}$, Le-Guen $\mathrm{M}$, et al. Bedside ultrasound assessment of positive end-expiratory pressure-induced lung recruitment. Am J Respir Crit Care Med 2011; 183: 341-347.

Soldati G, Testa A, Silva FR, et al. Chest ultrasonography in lung contusion. Chest 2006; 130: 533-538.

Volpicelli G. Lung sonography. J Ultrasound Med 2013; 32: 165-171.

Volpicelli G, Skurzak S, Boero E, et al. Lung ultrasound predicts well extravascular lung water but is of limited usefulness in the prediction of wedge pressure. Anesthesiology 2014; 121: 320-327.

Baldi G, Gargani L, Abramo A, et al. Lung water assessment by lung ultrasonography in intensive care: a pilot study. Intensive Care Med 2013; 39: 74-84.

Via G, Lichtenstein D, Mojoli F, et al. Whole lung lavage: a unique model for ultrasound assessment of lung aeration changes. Intensive Care Med 2010; 36: 999-1007.

Santos TM, Franci D, Coutinho CM, et al. A simplified ultrasound-based edema score to assess lung injury and clinical severity in septic patients. Am J Emerg Med 2013; 31: 1656-1660.

Lichtenstein D, Karakitsos D. Integrating lung ultrasound in the hemodynamic evaluation of acute circulatory failure (the fluid administration limited by lung sonography protocol). J Crit Care 2012; 27: 533.e11-9.

Platz E, Lattanzi A, Agbo C, et al. Utility of lung ultrasound in predicting pulmonary and cardiac pressures. Eur J Heart Fail 2012; 14: 1276-1284.

Lichtenstein DA, Mezière GA, Lagoueyte JF, et al. A-lines and B-lines: lung ultrasound as a bedside tool for predicting pulmonary artery occlusion pressure in the critically ill. Chest 2009; 136: 1014-1020.

Copetti R, Soldati G, Copetti P. Chest sonography: a useful tool to differentiate acute cardiogenic pulmonary edema from acute respiratory distress syndrome. Cardiovasc Ultrasound 2008; 6: 16.

Gargani L, Doveri M, D'Errico L, et al. Ultrasound lung comets in systemic sclerosis: a chest sonography hallmark of pulmonary interstitial fibrosis. Rheumatology (Oxford) 2009; 48: 1382-1387.

Tardella M, Gutierrez M, Salaffi F, et al. Ultrasound in the assessment of pulmonary fibrosis in connective tissue disorders: correlation with high-resolution computed tomography. J Rheumatol 2012; 39: 1641-1647. early systemic sclerosis. Ann Rheum Dis 2013; 72: 390-395. Moazedi-Fuerst FC, Kielhauser S, Brickmann K, et al. Sonographic assessment of interstitial lung disease in patients with rheumatoid arthritis, systemic sclerosis and systemic lupus erythematosus. Clin Exp Rheumatol 2015 33: S87-S91.

Al Deeb M, Barbic S, Featherstone R, et al. Point-of-care ultrasonography for the diagnosis of acute cardiogenic pulmonary edema in patients presenting with acute dyspnea: a systematic review and meta-analysis. Acad Emerg Med 2014; 21: 843-852.

Martindale JL, Wakai A, Collins SP, et al. Diagnosing acute heart failure in the emergency department: a systematic review and meta-analysis. Acad Emerg Med 2016; 23: 223-242.

Bataille B, Riu B, Ferre F, et al. Integrated use of bedside lung ultrasound and echocardiography in acute respiratory failure: a prospective observational study in ICU. Chest 2014; 146: 1586-1593.

Chira R, Chira A, Mircea PA. Intrathoracic tumors in contact with the chest wall - ultrasonographic and computed tomography comparative evaluation. Med Ultrason 2012; 14: 115-119.

Bandi V, Lunn W, Ernst A, et al. Ultrasound vs. CT in detecting chest wall invasion by tumor: a prospective study. Chest 2008; 133: 881-886.

Suzuki N, Saitoh T, Kitamura S. Tumor invasion of the chest wall in lung cancer: diagnosis with US. Radiology 1993; 187: 39-42.

Koyanagi T, Kawaharada N, Kurimoto Y, et al. Examination of intercostal arteries with transthoracic Doppler sonography. Echocardiography 2010; 27: 17-20.

Salamonsen M, Ellis S, Paul E, et al. Thoracic ultrasound demonstrates variable location of the intercostal artery. Respiration 2012; 83: 323-329.

Salamonsen M, Dobeli K, McGrath D, et al. Physician-performed ultrasound can accurately screen for a vulnerable intercostal artery prior to chest drainage procedures. Respirology 2013; 18: 942-947.

Hew M, Rahman N. Preventing intercostal vessel trauma: ultrasound to the rescue once more? Respirology 2013 18: 891-892.

Leyd T, Tang YM, Benson MD, et al. Diaphragmatic paralysis: the use of M mode ultrasound for diagnosis in adults. Spinal Cord 2006; 44: 505-508. Gerscovich EO, Cronan M, McGa
J Ultrasound Med 2001; 20: 597-604. Cohn D, Benditt JO, Eveloff S, et al. Diaphragm thickening during inspiration. J Appl Physiol 1997; 83: 291-296. Umbrello M, Formenti P, Longhi D, et al. Diaphragm ultrasound as indicator of respiratory effort in critically il patients undergoing assisted mechanical ventilation: a pilot clinical study. Crit Care 2015; 19: 161.

Ferrari G, De Filippi G, Elia F, et al. Diaphragm ultrasound as a new index of discontinuation from mechanical ventilation. Crit Ultrasound J 2014; 6: 8.

Grosu HB, Lee YI, Lee J, et al. Diaphragm muscle thinning in patients who are mechanically ventilated. Chest 2012; 142: 1455-1460.

Goligher EC, Fan E, Herridge MS, et al. Evolution of diaphragm thickness during mechanical ventilation. Impact of inspiratory effort. Am J Respir Crit Care Med 2015; 192: 1080-1088.

Kim WY, Suh HJ, Hong SB, et al. Diaphragm dysfunction assesse
from mechanical ventilation. Crit Care Med 2011; 39: 2627-2630.

Vivier E, Mekontso Dessap A, Dimassi S, et al. Diaphragm ultrasonography to estimate the work of breathing during non-invasive ventilation. Intensive Care Med 2012; 38: 796-803.

Silva S, Biendel C, Ruiz J, et al. Usefulness of cardiothoracic chest ultrasound in the management of acute respiratory failure in critical care practice. Chest 2013; 144: 859-865. 
114 Esteban A, Ferguson ND, Meade MO, et al. Evolution of mechanical ventilation in response to clinical research. Am J Respir Crit Care Med 2008; 177: 170-177.

115 Bellani G, Laffey JG, Pham T, et al. Epidemiology, patterns of care, and mortality for patients with acute respiratory distress syndrome in intensive care units in 50 countries. JAMA 2016; 315: 788-800.

116 Volpicelli G, Mussa A, Garofalo G, et al. Bedside lung ultrasound in the assessment of alveolar-interstitial syndrome. Am J Emerg Med 2006; 24: 689-696.

117 Combes A, Mokhtari M, Couvelard A, et al. Clinical and autopsy diagnoses in the intensive care unit: a prospective study. Arch Intern Med 2004; 164: 389-392.

118 Tejerina E, Esteban A, Fernández-Segoviano P, et al. Clinical diagnoses and autopsy findings: discrepancies in critically ill patients*. Crit Care Med 2012; 40: 842-846.

119 Xirouchaki N, Kondili E, Prinianakis G, et al. Impact of lung ultrasound on clinical decision making in critically ill patients. Intensive Care Med 2014; 40: 57-65.

120 Goffi A, Pivetta E, Lupia E, et al. Has lung ultrasound an impact on the management of patients with acute dyspnea in the emergency department? Crit Care 2013; 17: R180.

121 Laursen CB, Sloth E, Lassen AT, et al. Point-of-care ultrasonography in patients admitted with respiratory symptoms: a single-blind, randomised controlled trial. Lancet Respir Med 2014; 2: 638-646.

122 Gordon CE, Feller-Kopman D, Balk EM, et al. Pneumothorax following thoracentesis: a systematic review and meta-analysis. Arch Intern Med 2010; 170: 332-339.

123 Kohan JM, Poe RH, Israel RH, et al. Value of chest ultrasonography versus decubitus roentgenography for thoracentesis. Am Rev Respir Dis 1986; 133: 1124-1126.

124 Perazzo A, Gatto P, Barlascini C, et al. Can ultrasound guidance reduce the risk of pneumothorax following thoracentesis? J Bras Pneumol 2014; 40: 6-12.

125 Goligher EC, Leis JA, Fowler RA, et al. Utility and safety of draining pleural effusions in mechanically ventilated patients: a systematic review and meta-analysis. Crit Care 2011; 15: R46. Patel PA, Ernst FR, Gunnarsson CL. Ultrasonography guidance reduces complications and costs associated with thoracentesis procedures. J Clin Ultrasound 2012; 40: 135-141.

Mercaldi CJ, Lanes SF. Ultrasound guidance decreases complications and improves the cost of care among patients undergoing thoracentesis and paracentesis. Chest 2013; 143: 532-538.

128 Hooper C, Lee YC, Maskell N et al. Investigation of a unilateral pleural effusion in adults: British Thoracic Society Pleural Disease Guideline 2010. Thorax 2010; 65: Suppl., ii4-iil7.

129 Hooper CE, Welham SA, Maskell NA, et al. Pleural procedures and patient safety: a national BTS audit of practice. Thorax 2015; 70: 189-191.

130 Lafontaine N, Joosten SA, Steinfort D, et al. Differential implementation of special society pleural guidelines according to craft-group: impetus toward cross-specialty guidelines? Clin Med (Lond) 2014; 14: 361-366.

131 Duncan DR, Morgenthaler TI, Ryu JH, et al. Reducing iatrogenic risk in thoracentesis: establishing best practice via experiential training in a zero-risk environment. Chest 2009; 135: 1315-1320.

132 Hannan LM, Steinfort DP, Irving LB, et al. Direct ultrasound localisation for pleural aspiration: translating evidence into action. Intern Med J 2014; 44: 50-56.

133 Bossuyt PM, Irwig L, Craig J, et al. Comparative accuracy: assessing new tests against existing diagnostic pathways. BMJ 2006; 332: 1089-1092.

134 Moons KG, Biesheuvel CJ, Grobbee DE. Test research versus diagnostic research. Clin Chem 2004; 50: 473-476.

135 Lord SJ, Irwig L, Bossuyt PM. Using the principles of randomized controlled trial design to guide test evaluation. Med Decis Making 2009; 29: E1-E12.

136 Bossuyt PM, Reitsma JB, Bruns DE, et al. STARD 2015: an updated list of essential items for reporting diagnostic accuracy studies. BMJ 2015; 351: h5527.

137 Scott IA, Greenberg PB, Poole PJ. Cautionary tales in the clinical interpretation of studies of diagnostic tests. Intern Med J 2008; 38: 120-129.

138 Leeflang MM, Deeks JJ, Gatsonis C, et al. Systematic reviews of diagnostic test accuracy. Ann Intern Med 2008; 149: 889-897.

139 Liberati A, Altman DG, Tetzlaff J, et al. The PRISMA statement for reporting systematic reviews and meta-analyses of studies that evaluate healthcare interventions: explanation and elaboration. BMJ 2009; 339: b2700.

140 Whiting PF, Rutjes AW, Westwood ME, et al. QUADAS-2: a revised tool for the quality assessment of diagnostic accuracy studies. Ann Intern Med 2011; 155: 529-536.

141 Cochrane Methods. Handbook for DTA reviews. http://methods.cochrane.org/sdt/handbook-dta-reviews Date last accessed: April 24, 2016

142 Schünemann HJ, Oxman AD, Brozek J, et al. Grading quality of evidence and strength of recommendations for diagnostic tests and strategies. BMJ 2008; 336: 1106-1110.

143 Bossuyt PM, Reitsma JB, Linnet K, et al. Beyond diagnostic accuracy: the clinical utility of diagnostic tests. Clin Chem 2012; 58: 1636-1643.

144 Brown SM, Kasal J. Bedside ultrasound in the intensive care unit: where is the evidence? Semin Respir Crit Care Med 2015; 36: 878-889.

145 National Heart, Lung, and Blood Institute Acute Respiratory Distress Syndrome (ARDS) Clinical Trials Network, Wheeler AP, Bernard GR, et al. Pulmonary-artery versus central venous catheter to guide treatment of acute lung injury. N Engl J Med 2006; 354: 2213-2224.

146 Marik PE. Obituary: pulmonary artery catheter 1970 to 2013. Ann Intensive Care 2013; 3: 38.

147 Rodger M, Ramsay T, Fergusson D. Diagnostic randomized controlled trials: the final frontier. Trials 2012; $13: 137$.

148 Canadian Critical Care Trials Group. A randomized trial of diagnostic techniques for ventilator-associated pneumonia. N Engl J Med 2006; 355: 2619-2630.

149 Gazelle GS, Kessler L, Lee DW, et al. A framework for assessing the value of diagnostic imaging in the era of comparative effectiveness research. Radiology 2011; 261: 692-698.

150 Mueller C, Scholer A, Laule-Kilian K, et al. Use of B-type natriuretic peptide in the evaluation and management of acute dyspnea. N Engl J Med 2004; 350: 647-654.

151 Colli A, Prati D, Fraquelli M, et al. The use of a pocket-sized ultrasound device improves physical examination: results of an in- and outpatient cohort study. PLoS One 2015; 10: e0122181. 